\title{
Measurement of Transport Activities of Bile Acids in Human Multidrug Resistance-Associated Protein 3 Using Liquid Chromatography-Tandem Mass Spectrometry
}

\author{
Kana YamaguchI,* Tsuyoshi MuraI, ${ }^{*}$ Hikaru YabuUCHI,** and Takao Kurosawa*广 \\ *Faculty of Pharmaceutical Sciences, Health Sciences University of Hokkaido, Kanazawa, Ishikari-Tobetsu, \\ Hokkaido 061-0293, Japan \\ **Office of Collaborative Research and Technology Development, Kobe University, 1-1 Rokkodai, Nada, \\ Kobe 657-8501, Japan
}

\begin{abstract}
A method has been developed for the measurement of transport activities in membrane vesicles obtained from human multidrug resistance-associated protein 3 -expressing Sf9 cells for $1 \beta$-hydroxy-, $6 \alpha$-hydroxy- and unsaturated bile acids by high-performance liquid chromatography-electrospray ionization-tandem mass spectrometry. Calibration curves for the bile acids were linear over the range of 10 to $2000 \mathrm{pmol} / \mathrm{mL}$, and the detection limit was less than $2 \mathrm{pmol} / \mathrm{mL}$ for all bile acids using selected reaction monitoring analysis. The method was applied to measurements of adenosine triphosphate-dependent transport activities of the membrane vesicles for the above-mentioned hydroxylated and unsaturated bile acids. The present study demonstrated that the human multidrug resistance-associated protein 3 vesicles accepted 1 $1 \beta$-, $6 \alpha$-hydroxylated and unsaturated bile acids along with common bile acids, such as glycocholic acid and taurolithocholic acid 3-sulfate. The developed method is useful for measurements of bile acid transport activities.
\end{abstract}

(Received December 29, 2009; Accepted January 21, 2010; Published March 10, 2010)

\section{Introduction}

Biliary excretion of bile acids is mediated by canalicular adenosine triphosphate-binding cassette $(\mathrm{ABC})$ transporters, such as multidrug resistance-associated protein 2 (MRP2, ABCC2) and bile salt export pumps (BSEP, ABCB11)., Canalicular secretion of bile acids constitutes the major driving force for the generation of bile flow. Biliary excretion of monovalent bile acids, such as taurine- and glycine-conjugated bile acids, is mediated by BSEP, and divalent bile acids conjugated with sulfuric acid or glucronic acids are excreted into bile by MRP2. ${ }^{1,2}$ It is believed that any dysfunction of these transporters induces cholestasis. ${ }^{1,2}$ Mutations in MRP2 lead to Dubin-Johnson syndrome, and mutations in BSEP cause progressive familial intrahepatic cholestasis type 2 (PFIC-2). ${ }^{1,2}$ In contrast to MRP2 and BSEP, multidrug resistance-associated protein 3 (MRP3, ABCC3) localized at the basolateral membrane in hepatocytes excretes organic anions and bile acids from the hepatocytes to the sinusoid. ${ }^{3,4}$ Human MRP3 (hMRP3) has been shown to transport not only monovalent bile acids, but also divalent bile acids. ${ }^{4-6}$ Human MRP3 transports monovalent bile acids, such as glycocholic acid (G-CA) at high rates, even if at low affinity. ${ }^{4,5}$ Divalent bile acids, such as taurolithocholic acid-3-sulfate (T-LCA-3S) and hyocholic acid-glucuronide ( $3 \alpha, 6 \alpha, 7 \alpha$-trihydroxy- $5 \beta$-cholan-24-oic acid glucuronide), are transported by hMRP3 with high affinity. ${ }^{6,7}$ Moreover, hMRP3 expression is highly induced in hepatocytes under cholestatic

† To whom correspondence should be addressed.

E-mail: kurosawa@hoku-iryo-u.ac.jp conditions. ${ }^{3,8,9}$ It is thought that hMRP3 may compensate for the impaired functions of MRP2 and BSEP, and that hMRP3 functions as an efflux transporter from hepatocytes to circulating blood to switch the excretion route for organic anions, including bile acids, from bile to urine under pathologic conditions. ${ }^{3,8,9}$ The transport properties of bile acids mediated by hMRP3 have been investigated by examining the ATP-dependent transport of common bile acids, such as G-CA, taurocholic acid (T-CA) and T-LCA-3S in isolated bile canalicular membrane vesicles or in membrane vesicles obtained from hMRP3-expressing cells. ${ }^{4-6}$ In those investigations, bile acids labeled with a radioactive isotope (RI) have been widely used as substrates for hMRP3 vesicles. However, the transport properties of hMRP3 for unusual bile acids, such as $1 \beta$ - and $6 \alpha$-hydroxylated bile acids and unsaturated bile acids ( $3 \beta$-hydroxy-5-cholenoic acid and $7 \alpha, 12 \alpha$-dihydroxy-3-oxo-4-cholenoic acid), have not been established because of a difficulty in obtaining these RI-labeled bile acids.

$1 \beta$ - and $6 \alpha$-hydroxylated bile acids are peculiar bile acids that are excreted mainly in the urine or meconium of neonates. ${ }^{10-13}$ Unsaturated bile acids have been found in biological fluids of patients with severe liver disease. ${ }^{14-19}$ The transport of these bile acids by hMRP3 may be affected, since their structures and physical properties are significantly different from those of the common bile acids that are present in biological fluids in humans.

In our previous study, measurements of transport activities of these unusual bile acids in membrane vesicles obtained from hBSEP-expressing Sf9 cells were carried out by high-performance liquid chromatography-electrospray ionizationmass spectrometry (LC-ESI-MS) using a selected ion-monitoring 


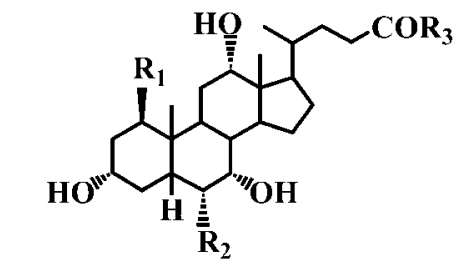

T-CA-1 $\beta-0 l: \mathrm{R}_{1}=\mathrm{OH}, \mathrm{R}_{2}=\mathrm{H}, \mathrm{R}_{3}=\mathrm{NH}\left(\mathrm{CH}_{2}\right)_{2} \mathrm{SO}_{3} \mathrm{H}$ T-CA- $6 \alpha-0 l: \mathrm{R}_{1}=\mathrm{H}, \mathrm{R}_{2}=\mathrm{OH}, \mathrm{R}_{3}=\mathrm{NH}\left(\mathrm{CH}_{2}\right)_{2} \mathrm{SO}_{3} \mathrm{H}$ G-CA-1 $\beta$-ol : $\mathbf{R}_{1}=\mathrm{OH}, \mathrm{R}_{2}=\mathrm{H}, \mathrm{R}_{3}=\mathrm{NHCH}_{2} \mathrm{COOH}$ G-CA- $\alpha \alpha-0$ : : $\mathrm{R}_{1}=\mathrm{H}, \mathrm{R}_{2}=\mathrm{OH}, \mathrm{R}_{3}=\mathrm{NHCH}_{2} \mathrm{COOH}$

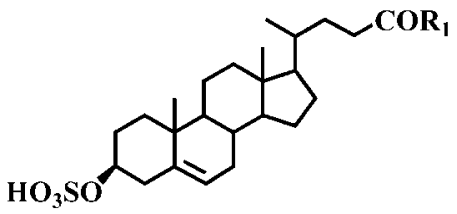
$\mathrm{T}-\Delta^{5}-3 \beta-\mathrm{S}: \mathrm{R}_{1}=\mathrm{NH}\left(\mathrm{CH}_{2}\right)_{2} \mathrm{SO}_{3} \mathrm{H}$ $\mathrm{G}-\Delta^{5}-3 \beta-\mathrm{S}: \mathrm{R}_{1}=\mathrm{NHCH}_{2} \mathrm{COOH}$

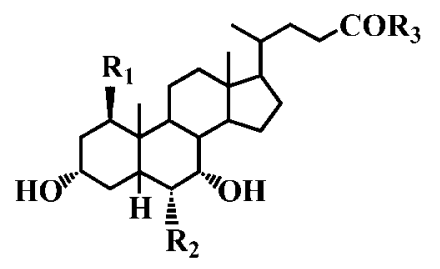

T-CDCA-1 $\beta-0$ : : $\mathrm{R}_{1}=\mathrm{OH}, \mathrm{R}_{2}=\mathrm{H}, \mathrm{R}_{3}=\mathrm{NH}\left(\mathrm{CH}_{2}\right)_{2} \mathrm{SO}_{3} \mathrm{H}$ T-CDCA-6 $\alpha$-0l : $\mathrm{R}_{\mathbf{1}}=\mathrm{H}, \mathrm{R}_{2}=\mathrm{OH}, \mathrm{R}_{3}=\mathrm{NH}\left(\mathrm{CH}_{2}\right)_{2} \mathrm{SO}_{3} \mathrm{H}$ G-CDCA-1 $\beta-01: \mathrm{R}_{1}=\mathrm{OH}, \mathrm{R}_{2}=\mathrm{H}, \mathrm{R}_{3}=\mathrm{NHCH}_{2} \mathrm{COOH}$ G-CDCA- $\alpha-01: \mathbf{R}_{1}=\mathrm{H}, \mathrm{R}_{2}=\mathrm{OH}, \mathrm{R}_{3}=\mathrm{NHCH}_{2} \mathrm{COOH}$<smiles>[R]C(=O)CCC(C)C1CCC2C3C(C[C@H](O)[C@@H]12)C1(C)CCC(=O)C=C1C[C@H]3O</smiles>

T-CA- $\Delta^{4}-3$-one: $\mathrm{R}_{1}=\mathrm{NH}\left(\mathrm{CH}_{2}\right)_{2} \mathrm{SO}_{3} \mathrm{H}$ G-CA- $\Delta^{4}-3$-one: $\mathrm{R}_{1}=\mathrm{NHCH}_{2} \mathrm{COOH}$

Fig. 1 Structures of bile acids.

method. ${ }^{20}$ However, the sensitivity for measurements of the transport activities of glycine- and taurine-conjugated bile acids mediated by hMRP3-expressing vesicles is still unsatisfactory, because the affinities for monovalent bile acids of hMRP3 are lower than those of hBSEP.

In recent years, high-performance liquid chromatographyelectrospray ionization coupled to tandem mass spectrometry (LC-ESI-MS/MS) has been developed for the determination of common bile acids in human biological fluids. ${ }^{21-25}$ The LC-ESI-MS/MS method is extremely sensitive for the determination of common bile acids, and it may be applicable for measurements of bile acid transport activities by hMRP3 vesicles without using RI labels. The present paper deals with a highly sensitive method for the determination of unusual bile acids, including common bile acids by the LC-ESI-MS/MS method and its application to measurements of ATP-dependent transport activities of bile acids in membrane vesicles obtained from hMRP3-expressing Sf9 cells.

\section{Experimental}

\section{Reagents and chemicals}

T-CA and G-CA were purchased from Sigma Chemical Co. (St. Louis, MO) and used after chromatographic purification. Glycine- and taurine-conjugated bile acids and bile acid 3 -sulfates were all stock samples synthesized in our laboratory. ${ }^{26-29}$ Chemical structures of $1 \beta$ - and $6 \alpha$-hydroxylated bile acids, unsaturated bile acids and their abbreviations are

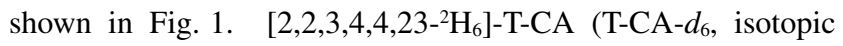
purity $>98.5 \%$ ) was used as an internal standard (IS) for the determination of bile acids by LC-ESI-MS/MS. An Oasis HLB 96-well plate cartridge (Waters Co., Milford, MA) was washed successively with ethanol $(0.5 \mathrm{~mL})$ and water $(1 \mathrm{~mL})$ prior to use. Adenosine triphosphate disodium salt (ATP) and adenosine monophosphate disodium salt (AMP) were obtained from Oriental Yeast (Tokyo, Japan). Human MRP3-expressing Sf9 membrane vesicles were obtained from GenoMembrane, Inc. (Kanagawa, Japan). All other reagents were of analytical grade.

\section{$L C$-ESI-MS/MS}

LC-ESI-MS/MS analysis was performed using an API4000 Q-Trap hybrid triple quadrupole linear ion-trap mass spectrometer (Applied Biosystems/MDS SCIEX, Concord, Canada) equipped with an ESI probe. High-purity nitrogen was produced by a nitrogen generator, 12E-SDA (System Instruments, Tokyo, Japan). The ion source was operated in the negative ion mode using the following settings: ion spray voltage, $-4000 \mathrm{~V}$; ion source heater temperature, $400^{\circ} \mathrm{C}$; source gas 1, 50 psi; source gas 2, 80 psi; curtain gas setting, 30 psi. Analytes were monitored by selected reaction monitoring (SRM). Mass transitions and MS parameters are given in Table 1. The gradient chromatographic separation of bile acids was performed on an Ascentis Express C18 column (50 mm $\times$ $2.1 \mathrm{~mm}$ i.d., $2.7-\mu \mathrm{m}$ particles, Supelco, Bellefont, PA) at ambient temperature. Mobile phase A was $15 \%$ acetonitrile $(\mathrm{MeCN}) / 10 \mathrm{mM}$ ammonium acetate ( $\mathrm{pH} 7.0$ adjusted by adding aqueous ammonia solution), and mobile phase $\mathrm{B}$ was $80 \%$ $\mathrm{MeCN} / 10 \mathrm{mM}$ ammonium acetate ( $\mathrm{pH} 7.0$ adjusted by adding aqueous ammonia solution), used at a flow rate of $0.25 \mathrm{~mL} / \mathrm{min}$ and delivered by a 1200 Series binary pump (1312B, Agilent Technologies, Palo Alto, CA). Gradient elution was performed with $100 \%$ A for $0.2 \mathrm{~min}$ and a linear increase to $60 \% \mathrm{~B}$ until $10 \mathrm{~min}$.

\section{Preparation standards}

For preparing standard stock solutions, glycine-conjugated, taurine-conjugated and sulfated bile acids were dissolved in methanol at a concentration of $200 \mu \mathrm{M}$. Samples were diluted to concentrations of $10,20,50,100,200,500,1000$, and $2000 \mathrm{pmol} / \mathrm{mL}$ using methanol. An IS stock solution containing $400 \mathrm{pmol} / \mathrm{mL}$ of T-CA- $d_{6}$ was also prepared in methanol. A $50-\mu \mathrm{L}$ aliquot of each standard solution was mixed with a $50-\mu \mathrm{L}$ IS solution and evaporated under nitrogen gas at room temperature. The residue was dissolved in $50 \mu \mathrm{L}$ of mobile phase $\mathrm{A}$, and $5 \mu \mathrm{L}$ of this solution was injected into the LC-ESI-MS/MS system. Calibration curves were constructed by plotting the relative peak area of each bile acid to that of IS against the amounts of the corresponding bile acid. 
Table 1 LC-ESI-MS/MS parameters of reference bile acids

\begin{tabular}{|c|c|c|c|c|c|c|}
\hline Bile acid & {$[\mathrm{M}-\mathrm{H}]^{-}, m / z$} & SRM transition & $\mathrm{CE}^{\mathrm{a}} / \mathrm{V}$ & Retention time/min & Linear regression $^{\mathrm{b}}$ equation & $\mathrm{LOD}^{\mathrm{c}} / \mathrm{pmol} \mathrm{mL} \mathrm{mL}^{-1}$ \\
\hline $\mathrm{T}-\mathrm{CA}$ & 514.3 & $514.3 \rightarrow 80.0$ & 124 & 6.4 & $A=5.8 \times 10^{-3} C-0.015^{\mathrm{d}}$ & 1.2 \\
\hline T-CA- $1 \beta$-ol & 530.3 & $530.3 \rightarrow 80.0$ & 130 & 3.8 & $A=3.7 \times 10^{-3} C-0.037$ & 1.1 \\
\hline T-CA- $6 \alpha-\mathrm{ol}$ & 530.3 & $530.3 \rightarrow 80.0$ & 130 & 4.7 & $A=4.6 \times 10^{-3} C-0.052$ & 1.1 \\
\hline T-CDCA- $1 \beta$-ol & 514.3 & $514.3 \rightarrow 80.0$ & 124 & 4.6 & $A=5.2 \times 10^{-3} C+0.042$ & 1.2 \\
\hline T-CDCA- $6 \alpha-\mathrm{ol}$ & 514.3 & $514.3 \rightarrow 80.0$ & 124 & 5.9 & $A=5.2 \times 10^{-3} C+0.010$ & 1.2 \\
\hline $\mathrm{T}-\mathrm{CA}-\Delta^{4}-3$-one & 510.3 & $510.3 \rightarrow 80.0$ & 124 & 5.2 & $A=6.4 \times 10^{-3} C-0.007$ & 2 \\
\hline $\mathrm{T}-\Delta^{5}-3 \beta-\mathrm{S}$ & 560.2 & $279.6 \rightarrow 462.3$ & 28 & 5.8 & $A=7.0 \times 10^{-3} C+0.018$ & 0.7 \\
\hline $\mathrm{G}-\mathrm{CA}$ & 464.3 & $464.3 \rightarrow 74.0$ & 78 & 6.1 & $A=6.9 \times 10^{-3} C-0.033$ & 0.8 \\
\hline G-CA- $1 \beta$-ol & 480.3 & $480.3 \rightarrow 74.0$ & 72 & 3.6 & $A=4.0 \times 10^{-3} C-0.042$ & 0.8 \\
\hline G-CA- $6 \alpha-$ ol & 480.3 & $480.3 \rightarrow 74.0$ & 72 & 4.5 & $A=4.0 \times 10^{-3} C-0.054$ & 0.8 \\
\hline G-CDCA- $1 \beta$-ol & 464.3 & $464.3 \rightarrow 74.0$ & 78 & 4.4 & $A=6.0 \times 10^{-3} C-0.052$ & 0.8 \\
\hline G-CDCA- $6 \alpha-\mathrm{ol}$ & 464.3 & $464.3 \rightarrow 74.0$ & 78 & 5.6 & $A=8.3 \times 10^{-3} C-0.076$ & 0.8 \\
\hline G-CA- $\Delta^{4}-3$-one & 460.3 & $460.3 \rightarrow 74.0$ & 76 & 5 & $A=7.0 \times 10^{-3} C-0.006$ & 2 \\
\hline $\mathrm{G}-\Delta^{5}-3 \beta-\mathrm{S}$ & 510.3 & $510.3 \rightarrow 430.3$ & 76 & 5.7 & $A=2.4 \times 10^{-3} C+0.072$ & 2 \\
\hline $\mathrm{T}-\mathrm{CA}-d_{6}(\mathrm{IS})$ & 520.3 & $520.3 \rightarrow 80.0$ & 130 & 6.4 & & \\
\hline
\end{tabular}

a. Collision energy. b. Calibration curves were constructed by plotting peak area ratios of each concentration of bile acid (10, 20, 40, 100,

$200,400,1000$ and $2000 \mathrm{pmol} / \mathrm{mL}$ ) to that of the IS (400 pmol/mL). c. Limit of detection. d. A, Peak area ratio; $C$, concentration (pmol $/ \mathrm{mL})$.

Studies on the transport of bile acids by membrane vesicles and preparation of analytical samples from incubation mixtures

The bile acids were dissolved in transport buffer $(50 \mathrm{mM}$ MOPS-Tris buffer, $\mathrm{pH} 7.0$, containing $70 \mathrm{mM} \mathrm{KCl}$ and $7.5 \mathrm{mM}$ $\mathrm{MgCl}_{2}$ ). Human MRP3-expressing Sf9 membrane vesicles were suspended in the transport buffer. As a control, membrane vesicles obtained from Sf9 cells transfected with the virus vector alone (mock vesicles) were also used. The membrane transport study was performed using a rapid filtration technique.,5,30 Briefly, the incubation mixture contained appropriate amounts of bile acid, $4 \mathrm{mM}$ ATP or AMP and $25 \mu \mathrm{g}$ of membrane protein in $50 \mu \mathrm{L}$ of the transport buffer. The mixture was incubated in a test tube at $37^{\circ} \mathrm{C}$. The transport reaction was stopped by the addition of $0.2 \mathrm{~mL}$ of ice-cold stop buffer (40 mM MOPS-Tris buffer, $\mathrm{pH} 7.0$, containing $70 \mathrm{mM} \mathrm{KCl}$ ). This mixture was passed through a $1.0-\mu \mathrm{m}$ glass fiber filter (Millipore Co., Billerica, MA), and then washed five times with $0.2 \mathrm{~mL}$ of ice-cold stop buffer. The bile acid transported into vesicles retained on the filter was eluted with ethanol $(1.4 \mathrm{~mL})$ after the addition of IS $(20 \mathrm{pmol})$ on the filter. After evaporation of the filtrate, the residue was dissolved in water $(0.2 \mathrm{~mL})$, and then the solution was applied to an Oasis HLB 96-well plate cartridge. The cartridge was washed with water $(0.4 \mathrm{~mL})$, and the bile acids were eluted with ethanol $(0.4 \mathrm{~mL})$. The eluate was evaporated to dryness under reduced pressure. The residue was dissolved with $50 \mu \mathrm{L}$ of mobile phase A, and an aliquot $(5 \mu \mathrm{L})$ was injected into the LC-ESI-MS/MS system.

ATP-dependent transport activity was calculated by subtracting the transport activity in the presence of AMP from that in the presence of ATP. In order to estimate the kinetic parameters for the uptake of bile acids by hMRP3, the initial uptake rate was fitted to the following equation by means of nonlinear least-square regression analysis using KaleidaGraph (Synergy Software, Reading, PA):

$$
v=V_{\max } x s /\left(K_{\mathrm{m}}+s\right),
$$

where $v, s, K_{\mathrm{m}}$ and $V_{\max }$ are the uptake rate $\left(\mathrm{pmol} \mathrm{min}^{-1} \mathrm{mg}^{-1}\right)$, concentration of bile acid $(\mu \mathrm{M})$, Michaelis-Menten constant $(\mu \mathrm{M})$ and maximum uptake rate $\left(\mathrm{pmol} \mathrm{min}^{-1} \mathrm{mg}^{-1}\right)$, respectively. The results are presented as means \pm standard error (SE).

\section{Results and Discussion}

It has been reported that unusual bile acids, such as $1 \beta$ - and $6 \alpha$-hydroxylated bile acids and unsaturated bile acids, exist mainly as glycine- and taurine-conjugated forms in biological fluids. ${ }^{10-13,19}$ In addition, monohydroxy bile acids, such as $3 \beta$-hydroxy-5-cholenoic acid exist mainly as 3 -sulfated forms of glycine- and taurine-conjugates. ${ }^{17,18}$ In the present study, glycine- and taurine-conjugated bile acids and bile acid 3-sulfates (Fig. 1) were used as substrates of hMRP3-expressing Sf9 membrane vesicles for following experiments.

\section{Quantitative analysis of bile acids by LC-ESI-MS/MS}

It has been reported that glycine- and taurine-conjugated bile acids are easily fragmented under the condition of low-energy collision-induced dissociation (CID), and that acidic group product ions formed from the deprotonated molecule $[\mathrm{M}-\mathrm{H}]^{-}$ were observed at $\mathrm{m} / \mathrm{z}, 74$ for glycine-conjugate bile acids and at $\mathrm{m} / \mathrm{z} 80$ for taurine-conjugate bile acids. It has also been reported that glycine- and taurine-conjugated bile acid 3-sulfates give doubly charged ions $[\mathrm{M}-2 \mathrm{H}]^{2-}$ in a solution of ammonium acetate-MeCN as a mobile phase. ${ }^{21-25}$ Goto et al. reported that taurine-conjugated bile acid 3-sulfates give a steroid nucleus-containing product ion $\left[\mathrm{M}-\mathrm{H}-\mathrm{H}_{2} \mathrm{SO}_{4}\right]^{-}$formed from doubly charged ion $[\mathrm{M}-2 \mathrm{H}]^{2-}$ with a low noise level, and also that glycine-conjugated bile acid 3-sulfates give the steroid nucleus-containing product ion $\left[\mathrm{M}-\mathrm{HSO}_{3}\right]^{-}$formed from the deprotonated molecule $[\mathrm{M}-\mathrm{H}]^{-}$under mild CID conditions. ${ }^{23}$ First we tested the fragmentation of deprotonated bile acids in the negative ion mode using $50 \% \mathrm{MeCN} / 10 \mathrm{mM}$ ammonium acetate ( $\mathrm{pH} 7.0$ adjusted by adding aqueous ammonia solution) as a mobile phase. The glycine- and taurine-conjugated forms of $1 \beta$ - and $6 \alpha$-hydroxylated bile acid and unsaturated bile acids (G-CA- $\Delta^{4}-3$-one and T-CA- $\Delta^{4}-3$-one) gave acidic group product ions at $m / z, 74$ and 80 , respectively. T- $\Delta^{5}-3 \beta-\mathrm{S}$ gave doubly charged ion $[\mathrm{M}-2 \mathrm{H}]^{2-}$ at $\mathrm{m} / \mathrm{z}, 279.7$ and gave product ion $\left[\mathrm{M}-\mathrm{H}-\mathrm{H}_{2} \mathrm{SO}_{4}\right]^{-}$at $m / z$ 462.3. G- $\Delta^{5}-3 \beta$-S gave the deprotonated molecule $[\mathrm{M}-\mathrm{H}]^{-}$at $\mathrm{m} / \mathrm{z} 510.3$, and gave the product ion $\left[\mathrm{M}-\mathrm{HSO}_{3}\right]^{-}$at $\mathrm{m} / \mathrm{z}$ 430.3. These results are consistent with previous reported findings. Therefore, we selected these product ions as monitoring ions for SRM analysis, and optimized the collision energy to obtain the highest signal-to-noise ratio 


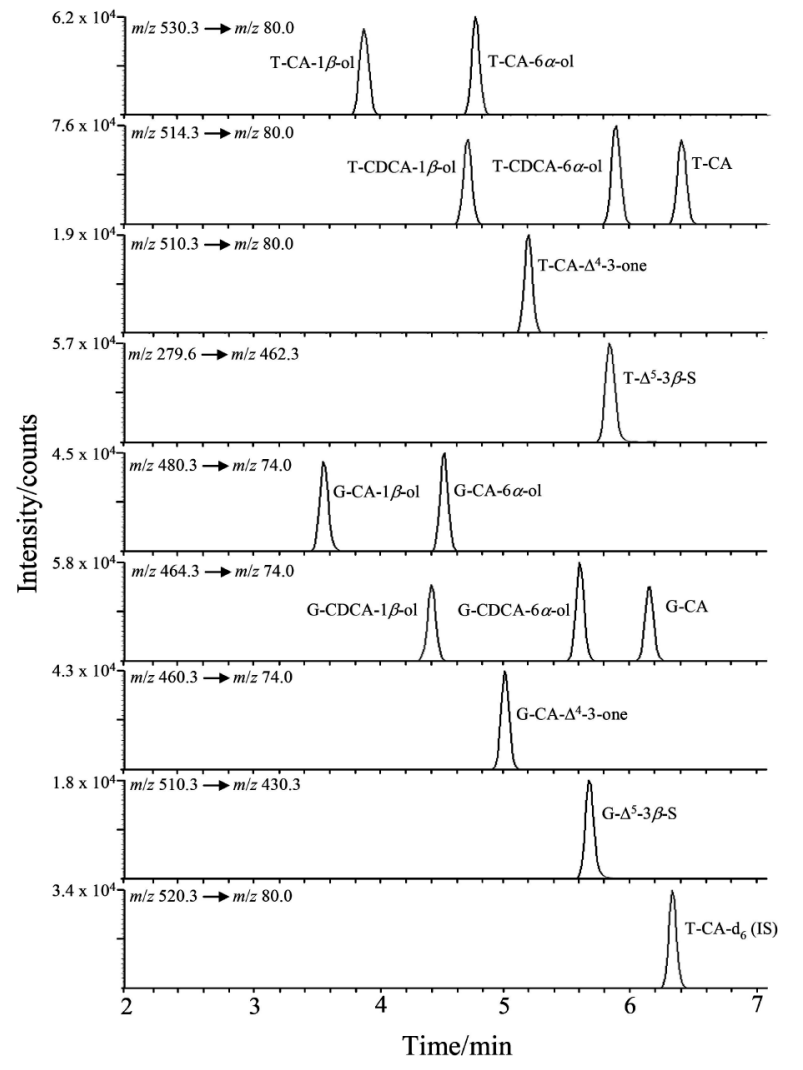

Fig. 2 Typical SRM chromatograms of authentic standards of bile acids.

(Table 1). Typical SRM chromatograms for authentic samples of fourteen bile acids are shown in Fig. 2, indicating the simultaneous separation and determination of all bile acids within $6.5 \mathrm{~min}$. Calibration curves were constructed by plotting the relative peak area of each bile acid to the IS against the amounts of the corresponding bile acid. A good linear relationship to each bile acid was obtained over the range of $10-2000 \mathrm{pmol} / \mathrm{mL}$, with linear correlation coefficients of more than 0.999 for all bile acids. The deviations of calibration standards were less than $10 \%(n=5)$ for all points in the calibration range. The detection limit was less than $2 \mathrm{pmol} / \mathrm{mL}$ $(S / N=5)$ for all bile acids using blank extracts of an incubation mixture with hMRP3-expressing membrane vesicles $(25 \mu \mathrm{g}$ of membrane protein), and was sufficient for application to the measurement of the ATP-dependent transport activities of bile acids in membrane vesicles obtained from hMRP3-expressing Sf9 cells. The linear regression equations, retention times, and detection limits for each bile acid are summarized in Table 1. Prior to LC-ESI-MS/MS analysis, the bile acid transported into hMRP3 vesicles retained on the glass fiber filter was eluted with ethanol. The bile acids were completely recovered from the first $1.4 \mathrm{~mL}$ of ethanol. After evaporation of the eluents, the residue was passed through an Oasis HLB 96-well plate cartridge to remove any impurities. The recovery rates through the clean-up procedure were tested by adding known concentrations of bile acids $(10,100$, and $1000 \mathrm{pmol} / \mathrm{mL})$ to blank extracts of an incubation mixture with hMRP3-expressing membrane vesicles. The relative recoveries of bile acids were obtained as 96.0 to $105.4 \%$ of the added amounts of their standard samples and coefficients of variation were less than $5 \%$ (Table 2).
Table 2 Relative recoveries of bile acids from extracts of an incubation mixture with hMRP3-expressing membrane vesicles

\begin{tabular}{|c|c|c|c|}
\hline \multirow[b]{2}{*}{ Bile acid } & \multicolumn{3}{|c|}{ Relative recovery $\left(\%\right.$, mean $\left.\pm \mathrm{SD}^{\mathrm{a}}, n=5\right)$} \\
\hline & $\begin{array}{l}\text { Concentration } \\
\text { added } / \\
10 \mathrm{pmol} \mathrm{mL}^{-1}\end{array}$ & $\begin{array}{l}\text { Concentration } \\
\text { added/ } \\
100 \mathrm{pmol} \mathrm{mL}^{-1}\end{array}$ & $\begin{array}{c}\text { Concentration } \\
\text { added/ } \\
1000 \text { pmol } \mathrm{mL}^{-}\end{array}$ \\
\hline T-CA & & & \\
\hline $\mathrm{T}-\mathrm{CA}-$ & & & \\
\hline T-CA- $6 \alpha-\mathrm{ol}$ & $99.2 \pm 5.0$ & & 101 \\
\hline $\mathrm{T}-\mathrm{CDC}$ & $100.9 \pm 3.1$ & & \\
\hline & & & \\
\hline T-CA- $\Delta^{4}-3$-one & $100.4 \pm 3$ & $100.9 \pm$ & \\
\hline $\mathrm{T}-\Delta^{5}-3 \beta-\mathrm{S}$ & & & \\
\hline & & & 104 \\
\hline & $99.2 \pm$ & & \\
\hline & $100.9 \pm$ & $100.4 \pm$ & 100 \\
\hline & & $101.3 \pm 1.9$ & \\
\hline & $101.6 \pm 1.2(1.2)$ & $96.9 \pm 2.9(3.0)$ & $105.4 \pm 0.9(0.8)$ \\
\hline G-CA- & $96.7 \pm 4.9(4.9)$ & $99.7 \pm 2.2(2.2)$ & $103.1 \pm 1.5$ \\
\hline $\mathrm{G}-\Delta^{5}-3 \beta-\mathrm{S}$ & $102.4 \pm 3.4(3.3)$ & $96.0 \pm 4.2(4.3)$ & $98.4 \pm 3.2$ \\
\hline
\end{tabular}

a. Standard deviation.

b. Values in parentheses represent the coefficient value.

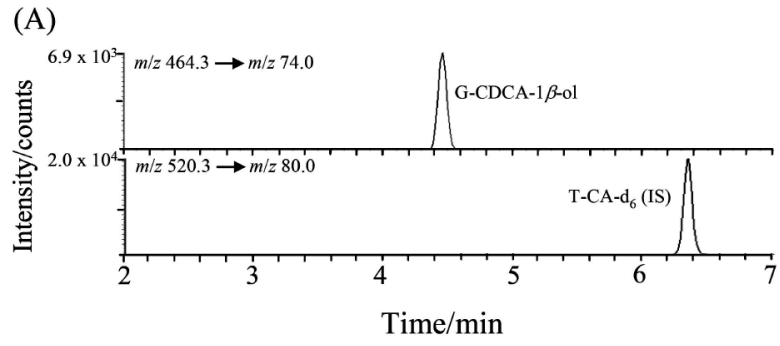

(B)

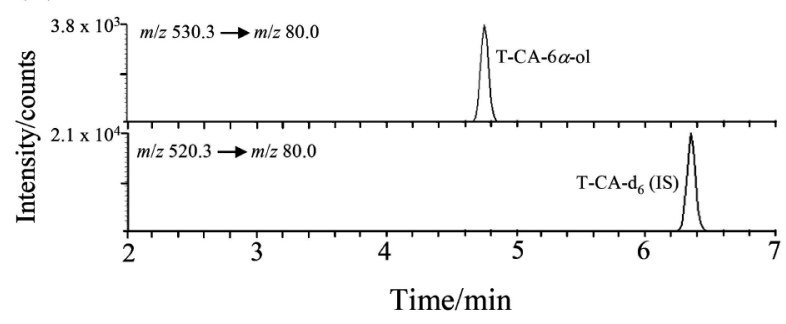

(C)

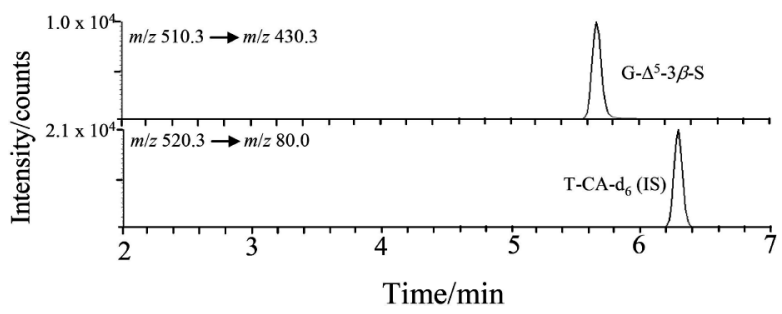

Fig. 3 Typical SRM chromatograms of bile acids in an incubation mixture of G-CDCA- $1 \beta$-ol (A), T-CA- $6 \alpha$-ol (B), and G- $\Delta^{5}-3 \beta-\mathrm{S}$ as a substrate with hMRP3-expressing membrane vesicles.

\section{Measurement of ATP-dependent transport activities}

The developed method was applied to measurements of the ATP-dependent transport activities of bile acids in membrane vesicles obtained from hMRP3-expressing Sf9 cells. Figure 3 shows typical SRM chromatograms of an incubation mixture of 


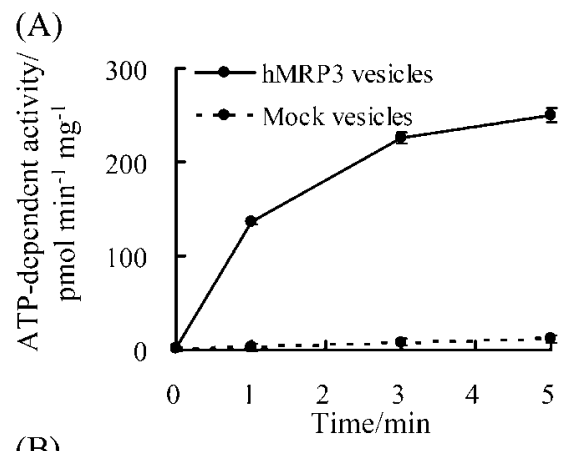

(B)

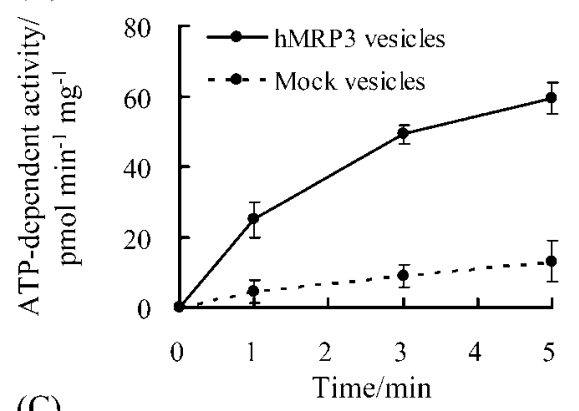

(C)

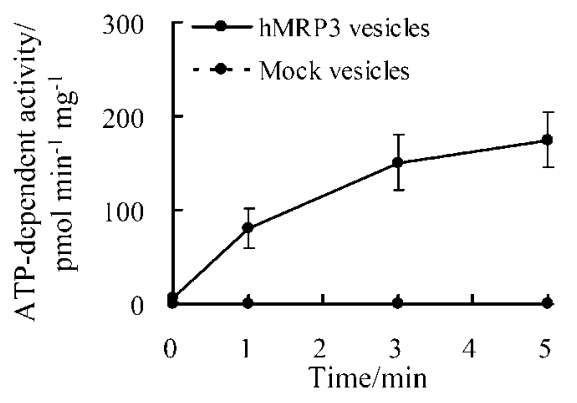

Fig. 4 Time-dependent uptake of G-CDCA- $1 \beta$-ol (A), T-CA- $6 \alpha$-ol (B), and G- $\Delta^{5}-3 \beta-\mathrm{S}$ (C) by hMRP3-expressing membrane vesicles. Membrane vesicles $(25 \mu \mathrm{g}$ of protein) from hMRP3 and mock-expressing Sf9 cells were incubated in a transport buffer (pH 7.0) containing $10 \mu \mathrm{M}$ of bile acid at $37^{\circ} \mathrm{C}$ in the presence of $4 \mathrm{mM}$ ATP or AMP. Results are shown as ATP-dependent transport, calculated by subtracting the transport in the presence of AMP from that in the presence of ATP. Each point and vertical bar represent the mean \pm SD of 3 determinations.

hMRP3-expressing membrane vesicles with G-CDCA-1 $\beta$-ol, T-CA- $6 \alpha-$ ol and G- $\Delta^{5}-3 \beta-\mathrm{S}$ as a substrate. All bile acids were clearly detected without endogenous contaminants. Figure 4 shows the ATP-dependent uptake of G-CDCA-1 $\beta$-ol, T-CA- $6 \alpha-\mathrm{ol}$ and G- $\Delta^{5}-3 \beta-\mathrm{S}$ obtained as the difference between uptake with ATP and that with AMP by hMRP3 and mock vesicles for $5 \mathrm{~min}$. The ATP-dependent uptake of bile acids by hMRP3-expressing membrane vesicles increased linearly up to $3 \mathrm{~min}$, while the increase in uptake was almost negligible with the mock vesicles. The time dependence of the ATP-dependent uptake of other bile acids was also observed (data not shown). The initial ATP-dependent uptakes of the studied bile acids by hMRP3-expressing membrane vesicles and mock vesicles are shown in Fig. 5. The hMRP3-expressing membrane vesicles showed an ATP-dependent uptake for glycine- and taurine-conjugated bile acids and bile acid 3-sulfates. The hMRP3 vesicles transported glycine-conjugated bile acids to a greater extent than taurine-conjugated bile acids. This result is in good accordance with previous reports, indicating that

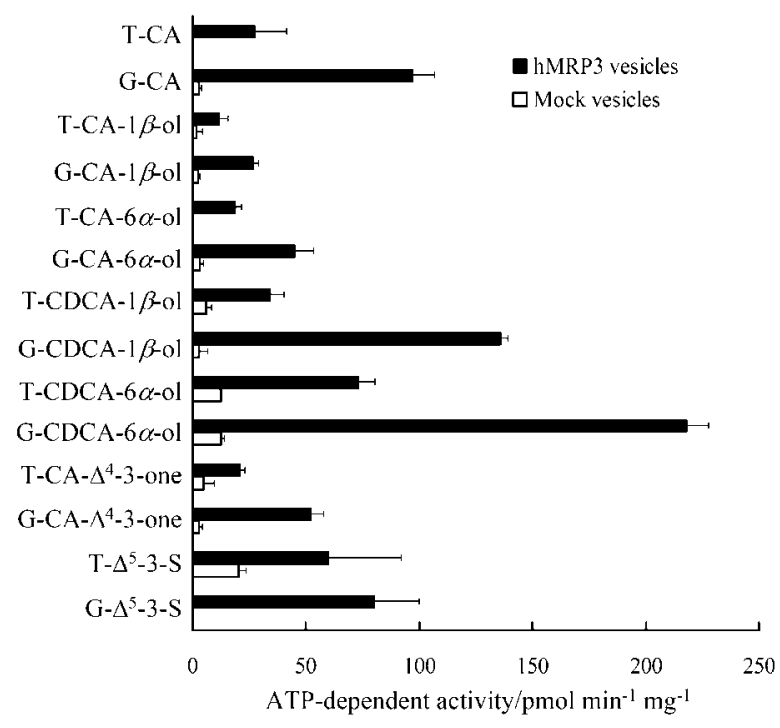

Fig. 5 ATP-dependent uptake of polyhydroxylated and unsaturated bile acids by hMRP3-expressing membrane vesicles. hMRP3expressing membrane vesicles or mock vesicles (each $25 \mu \mathrm{g}$ of protein) were incubated in a transport buffer containing bile acids $(10 \mu \mathrm{M})$ for $1 \mathrm{~min}$ at $37^{\circ} \mathrm{C}$ in the presence of $4 \mathrm{mM}$ ATP or AMP. ATP-dependent transport activity was calculated by subtracting the transport activity in the presence of AMP from that in the presence of ATP. Each value represents the mean \pm SD of 3 determinations.

ATP-dependent transport activities of glycine-conjugated bile acids in hMRP3 vesicles were higher than those of taurine-conjugated bile acids. ${ }^{4-6}$ We also found that the initial ATP-dependent transport uptake of G-CDCA- $1 \beta$-ol was comparable to that of G-CA, and that the uptake of G-CDCA- $6 \alpha$-ol was approximately 2-fold higher than that of G-CA. Moreover, the hMRP3-expressing membrane vesicles also showed a significant ATP-dependent uptake for divalent unsaturated bile acid 3 -sulfates (G- $\Delta^{5}-3 \beta-\mathrm{S}$ and T- $\Delta^{5}-3 \beta-\mathrm{S}$ ). The results are also consistent with previous reports indicating that bile acid 3-sulfates, such as T-LCA-3S, are substrates of hMRP $3 ., 4$

In this study, glycine-conjugated bile acids were transported more efficiently by hMRP3 vesicles, so we selected a series of glycine-conjugated bile acids as substrates to perform a kinetic analysis study to further characterized the hMRP3-mediated transportation of unusual bile acids. Figure $6 \mathrm{~A}$ shows the concentration dependence of the ATP-dependent uptake of G-CA. The uptake was saturable, and the values of the kinetic parameters, $K_{\mathrm{m}}$ and $V_{\max }$ (with SE), obtained by nonlinear least regression analysis for hMRP3 were $194 \pm 23 \mu \mathrm{M}$ and $2562 \pm 141 \mathrm{pmol} \mathrm{min}^{-1} \mathrm{mg}^{-1}$, respectively. The $K_{\mathrm{m}}$ value for G-CA was comparable to the previously reported value of the hMRP3-mediated transport of ${ }^{14} \mathrm{C}$-labeled G-CA $(248 \pm$ $113 \mu \mathrm{M}){ }^{5}{ }^{5}$ The hMRP3 vesicles showed low affinity and high capacity for G-CA. This result is consistent with previously reported findings that hMRP3 transports G-CA at high rates, albeit at low affinity. ${ }^{4-6}$ In addition to the G-CA uptake, the concentration dependence of the ATP-dependent transport activities of other glycine-conjugated bile acids in hMRP3 vesicles was also determined by LC-ESI-MS/MS. The concentration dependence of the ATP-dependent uptake of glycine-conjugated bile acids is also shown in Fig. 6 . The values of the kinetic parameters, $K_{\mathrm{m}}$ and $V_{\max }$, for unusual bile acids were determined in the same manner as that for G-CA. 


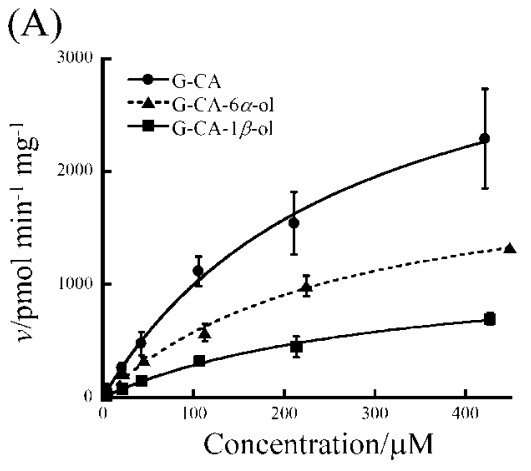

(B)

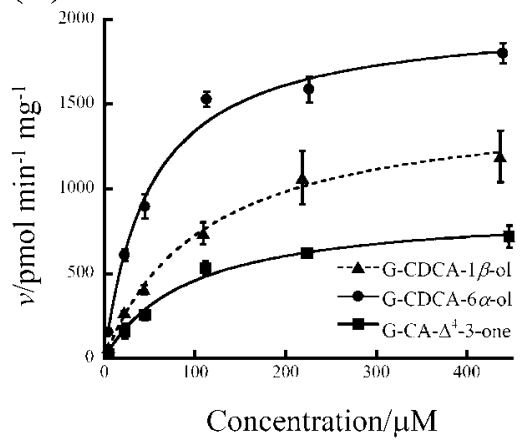

(C)

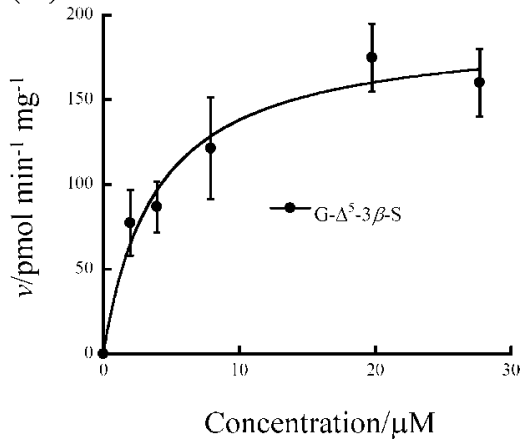

Fig. 6 Concentration dependence of the uptake of various glycine-conjugated bile acids by hMRP3-expressing membrane vesicles. Membrane vesicles $(25 \mu \mathrm{g}$ of protein) from hMRP3expressing Sf9 cells were incubated with various concentrations of bile acids with $4 \mathrm{mM}$ ATP or AMP in transport buffer for $1 \mathrm{~min}$ at $37^{\circ} \mathrm{C}$. ATP-dependent transport activity was calculated by subtracting the transport activity in the presence of AMP from that in the presence of ATP. Each value represents the mean \pm SD of 4 determinations.

The $K_{\mathrm{m}}, V_{\max }$ values are summarized in Table 3 . To compare the transport rates for unusual bile acids by hMRP3 vesicles, the intrinsic clearance $\left(V_{\max } / K_{\mathrm{m}}\right)$ values for each bile acid were also determined using the $K_{\mathrm{m}}$ and $V_{\max }$ values calculated by kinetic analysis (Table 3). The hMRP3 vesicles showed the transport of G- $\Delta^{5}-3 \beta$-S with the highest affinity $\left(K_{\mathrm{m}}\right.$ value: $\left.4 \pm 1 \mu \mathrm{M}\right)$ and $V_{\max } / K_{\mathrm{m}}$ value $\left(50 \pm 16 \mu \mathrm{L} \mathrm{min}{ }^{-1} \mathrm{mg}^{-1}\right)$ among the tested bile acids. The results are consistent with previous reports indicating that a divalent bile acid such as T-LCA-3S is a high-affinity substrate of hMRP3.,6 For monovalent bile acids, the affinities and $V_{\max } / K_{\mathrm{m}}$ values of the hMRP3 vesicles were significantly lower than those for G- $\Delta^{5}-3 \beta$-S. However, the $V_{\max } / K_{\mathrm{m}}$ values of G-CDCA- $1 \beta$-ol $\quad\left(14 \pm 2 \mu \mathrm{L} \mathrm{min}{ }^{-1} \mathrm{mg}^{-1}\right), \quad$ G-CA- $6 \alpha$-ol $\quad(8 \pm$

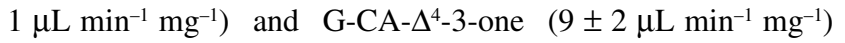
were comparable to that of G-CA $\left(13 \pm 2 \mu \mathrm{L} \mathrm{min}{ }^{-1} \mathrm{mg}^{-1}\right)$.
Table 3 Kinetic parameters of hMRP3-expressing membrane vesicles

\begin{tabular}{lccc}
\hline Bile acid (substrate) & $K_{\mathrm{m}} / \mu \mathrm{M}$ & $\begin{array}{c}V_{\max } / \mathrm{pmol} \\
\mathrm{min}^{-1} \mathrm{mg}^{-1}\end{array}$ & $\begin{array}{c}V_{\max } / K_{\mathrm{m}} \\
\mu \mathrm{min}^{-1} \mathrm{mg}^{-1}\end{array}$ \\
\hline G-CA & $194 \pm 23$ & $2562 \pm 141$ & $13 \pm 2$ \\
G-CA-1 $\beta$-ol & $329 \pm 58$ & $1220 \pm 117$ & $4 \pm 1$ \\
G-CA-6 $\alpha$-ol & $265 \pm 42$ & $2107 \pm 169$ & $8 \pm 1$ \\
G-CDCA-1 $\beta$-ol & $110 \pm 13$ & $1522 \pm 68$ & $14 \pm 2$ \\
G-CDCA-6 $\alpha$-ol & $53 \pm 12$ & $2041 \pm 170$ & $39 \pm 10$ \\
G-CA- $\Delta^{4}-3$-one & $93 \pm 16$ & $878 \pm 52$ & $9 \pm 2$ \\
G- $\Delta^{5}-3 \beta$-S & $4 \pm 1$ & $191 \pm 17$ & $50 \pm 16$ \\
\hline
\end{tabular}

The $K_{\mathrm{m}}$ and $V_{\max }$ values for G-CA and G-CDCA- $6 \alpha$-ol were determined by nonlinear least-squares regression analysis using the data shown in Fig. 6. The $K_{\mathrm{m}}$ and $V_{\max }$ values for other bile acids were determined in the same manner as that for G-CA and G-CDCA- $6 \alpha$-ol. Each value represents the mean $\pm \mathrm{SE}$ of 4 determinations.

In addition, the $V_{\max } / K_{\mathrm{m}}$ value for G-CDCA- $6 \alpha$-ol (39 \pm $10 \mu \mathrm{L} \mathrm{min}^{-1} \mathrm{mg}^{-1}$ ) was approximately 3-fold higher than that for G-CA. Although the hMRP3-expressing membrane vesicles showed an ATP-dependent uptake for G-CA-1 $\beta$-ol (Fig. 4), the value of $V_{\max } / K_{\mathrm{m}}$ for this bile acid $\left(4 \pm 1 \mu \mathrm{L} \mathrm{min}{ }^{-1} \mathrm{mg}^{-1}\right)$ was less than $1 / 3$ that for G-CA. The present study demonstrated that the hMRP3 vesicles accepted unusual bile acids, and transported glycine-conjugated unusual bile acids except, for G-CA- $1 \beta$-ol, as efficiently as common bile acids, such as G-CA and T-LCA-3S.

\section{Conclusion}

The use of the LC-ESI-MS/MS method for measurements of bile acid transport activities may provide much more precise information on the role and function of hMRP3. We demonstrated that unusual bile acids were substrates of hMRP3. We previously reported that the transport of unusual bile acids, such as $1 \beta$-hydroxylated bile acids and unsaturated bile acids by hBSEP-expressing membrane vesicles, was not observed. ${ }^{20}$ Human MRP3 may exhibit wider substrate specificity than hBSEP, and may play a key role in the excretion of unusual bile acids. The transport of unusual bile acids may be mediated by other bile acid transporters, such as multidrug resistance-associated protein 4 and MRP 2, which have a function in the transport of monovalent and divalent bile acids. ${ }^{3}$ Further studies on the transport properties of other bile acid transporters for unusual bile acids are in progress.

\section{References}

1. M. Trauner and J. L. Boyer, Physiol. Rev., 2003, 83, 633.

2. W. A. Alrefai and R. K. Gill, Pharm. Res., 2007, 24, 1803.

3. P. Borst, C. de Wolf, and K. van de Wetering, Pflugers Arch., 2007, 453, 661.

4. H. Akita, H. Suzuki, T. Hirohashi, H. Takikawa, and Y. Sugiyama, Pharm. Res., 2002, 19, 34.

5. H. Zeng, G. Liu, P. A. Rea, and G. D. Kruh, Cancer Res., 2000, 60, 4779.

6. N. Zelcer, T. Saeki, I. Bot, A. Kuil, and P. Borst, Biochem. J., 2003, 369, 23.

7. N. Zelcer, K. van de Wetering, R. de Waart, G. L. Scheffer, H. U. Marschall, P. R. Wielinga, A. Kuil, C. Kunne, A. 
Smith, M. van der Valk, J. Wijnholds, R. O. Elferink, and P. Borst, J. Hepatol., 2006, 44, 768.

8. G. L. Scheffer, M. Kool, M. de Haas, J. M. L. de Vree, A. C. L. M. Pijnenborg, D. K. Bosman, R. P. J. Oude Elferink, P. van der Valk, P. Borst, and R. J. Scheper, Lab. Invest., 2002, 82, 193.

9. G. Zollner, P. Fickert, D. Silbert, A. Fuchsbichler, H. U. Marschall, K. Zatloukal, H. Denk, and M. Trauner, J. Hepatol., 2003, 38, 717.

10. D. A. Piccoli, E. S. Maller, and J. B. Watkins, in "Pediatric Gastroenterology and Hepatology", ed. M. Gracey and V. Burke, 3rd ed., 1993, 835.

11. A. Kimura, R. Yamakawa, K. Ushijima, T. Fujisawa, N. Kuriya, H. Kato, T. Inokuchi, R. Mahara, T. Kurosawa, and M. Tohma, Hepatology, 1994, 20, 819.

12. M. Kumagai, A. Kimura, H. Takei, T. Kurosawa, K. Aoki, T. Inokuchi, and T. Matsuishi, J. Gastroenterol., 2007, 42, 904.

13. S. Ikegawa, N. Hirabayashi, T. Yoshimura, and M. Tohma, J. Chromatogr., 1992, 577, 229.

14. K. D. R. Setchell, F. J. Suchy, M. B. Welsh, L. Zimmer-Nechemias, J. Heubi, and W. F. Balistreri, J. Clin. Invest., 1988, 82, 2148.

15. Y. Yamato, A. Kimura, T. Inoue, T. Kurosawa, and H. Kato, Biol. Neonate, 2001, 80, 19.

16. K. Maeda, A. Kimura, Y. Yamato, and T. Matsuishi, Acta Paediatr., 2003, 92, 216.

17. J. Shoda, T. Osuga, K. Matsuura, R. Mahara, M. Tohma, N. Tanaka, Y. Matsuzaki, and H. Miyazaki, J. Lipid Res., 1989, $30,1233$.
18. K. D. R. Setchell, M. Schwarz, N. C. O'Connell, E. G. Lund, D. L. Davis, R. Lathe, H. R. Thompson, R. W. Tyson, R. J. Sokol, and D. W. Russell, J. Clin. Invest., 1998, 102, 1690.

19. T. Yoshimura, T. Taniguchi, T. Kurosawa, A. Kimura, and M. Tohma, J. Liq. Chromatogr., Relat. Technol., 1997, 20, 923.

20. K. Yamaguchi, T. Murai, H. Yabuuchi, and T. Kurosawa, Anal. Sci., 2009, 25, 1155.

21. S. Ikegawa, T. Yanagihara, N. Murao, H. Watanabe, J. Goto, and T. Niwa, J. Mass Spectrom., 1997, 32, 401.

22. I. Burkard, A. von Eckardstein, and K. M. Rentsch, J. Chromatogr., B, 2005, 826, 147.

23. T. Goto, K. T. Myint, K. Sato, O. Wada, G. Kakiyama, T. Iida, T. Hishinuma, N. Mano, and J. Goto, J. Chromatogr., B, 2007, 846, 69 .

24. K. Bentayeb, R. Batlle, C. Sanchez, C. Nerin, and C. Domeno, J. Chromatogr., B, 2008, 869, 1.

25. M. Scherer, C. Gnewuch, G. Schmitz, and G. Liebisch, $J$. Chromatogr., B, 2009, 877, 3920.

26. M. Tohma, R. Mahara, H. Takeshita, T. Kurosawa, and S. Ikegawa, Chem. Pharm. Bull., 1986, 34, 2890.

27. T. Kurosawa, R. Mahara, H. Nittono, and M. Tohma, Chem. Pharm. Bull., 1989, 37, 557.

28. A. Kallner, Acta Chem. Scand., 1967, 21, 322.

29. M. Tohma, H. Wajima, R. Mahara, T. Kurosawa, and I. Makino, Steroids, 1984, 44, 47.

30. T. Ishikawa, M. Muller, C. Klunemann, T. Schaub, and D. Keppler, J. Biol. Chem., 1990, 265, 19279. 